\title{
Contraceptive knowledge, attitudes, and use among women visiting primary healthcare centers in Abu Dhabi Island
}

\author{
Sumaiya Taheri $^{1 *}$, Amal Al Sereidi ${ }^{1}$, Shammah Al Mamari ${ }^{2}$, Ebtihal Darwish ${ }^{3}$
}

\begin{abstract}
${ }^{1}$ Department of Family Medicine Residency Program, Shaikh Khalifa Medical City, Abu Dhabi, UAE
${ }^{2}$ Department of Family Medicine Specialist, Ambulatory Healthcare Services, Abu Dhabi, UAE

${ }^{3}$ Department of Family Medicine Consultant, Ethraa Consultation Center, Dubai, UAE
\end{abstract}

Received: 04 March 2019

Accepted: 02 April 2019

\section{*Correspondence: \\ Dr. Sumaiya Taheri, \\ E-mail: sutaheri@seha.ae}

Copyright: () the author(s), publisher and licensee Medip Academy. This is an open-access article distributed under the terms of the Creative Commons Attribution Non-Commercial License, which permits unrestricted non-commercial use, distribution, and reproduction in any medium, provided the original work is properly cited.

\section{ABSTRACT}

Background: This study assessed contraceptive knowledge, attitudes, and use among women of reproductive age in Abu Dhabi Island.

Methods: A cross-sectional study was conducted in primary healthcare centers Al Bateen and Al Rawda in Abu Dhabi Island. Participants were women $(\mathrm{N}=384$; aged 18-54 years) who were married, widowed, divorced, or sexually active. Using a structured questionnaire, we examined their socio-demographic characteristics and their contraceptive knowledge, attitudes, and use.

Results: A total of $44.8 \%$ of the women were aged 30-39 years, $98.4 \%$ had university education and above, $56.7 \%$ were employed, and $69.4 \%$ had an adequate family income. Only $23.7 \%$ possessed good knowledge about contraceptive methods (e.g., indications/contraindications, side effects, and benefits). Further, $72.1 \%$ had used contraception before, while $48.3 \%$ were current users. The most commonly used methods were natural methods $(63.6 \%)$, followed by condoms (35.6\%), oral contraceptive pills (34\%), and intrauterine devices (33.7\%). Interestingly, only $4.6 \%$ held a negative attitude toward contraception, while $53.5 \%$ were in favor of using contraceptives. Family income and employment status were significantly related to contraceptive knowledge $(\mathrm{P}=$ 0.005 and .013 , respectively). Number of children, children's sex, and years of marriage were significantly related to contraception use $(\mathrm{P}<0.001,<0.001$, and 0.008 respectively).

Conclusions: Despite poor knowledge about contraception use, most women held favorable attitudes toward using them. About half the women were current contraception users, with natural methods being the most commonly practiced.

Keywords: Attitudes, Contraception, Knowledge, Practice

\section{INTRODUCTION}

According to the World Health Organization, family planning is defined as "the ability of individuals and couples to anticipate and attain their desired number of children and the spacing and timing of their births. It is achieved through use of contraceptive methods and the treatment of involuntary infertility". "The importance of family planning is clear from its benefits to individuals, as well as to families, communities, and societies. A woman's ability to space and limit her pregnancies has a direct impact on her well-being, and unintended pregnancies are associated with an array of negative health, economic, social, and psychological outcomes for women and children. ${ }^{2}$

Globally, use of modern contraception has risen slightly, from $54 \%$ in 1990 to $57.4 \%$ in $2015 .{ }^{1}$ According to 
numerous studies, the extent of contraception use varies according to cultural factors, age, parity, education, occupation, family attitude, motivation, and the availability of contraception. Further, lack of awareness, a negative attitude, misconception, fear of side effects, and cultural and religious beliefs limit the use of contraception. $^{2,3}$

During our literature review, we found that women's contraceptive knowledge, attitudes, and use varies across countries. Studies conducted in India, Ethiopia, and Saudi Arabia revealed that contraceptive methods were well known among women, women's attitudes varied depending on diverse factors, contraceptives were not commonly used, and the high awareness of contraceptive methods did not match women's pattern of contraception use. Causes for these findings were determined to be socioeconomic factors, religious beliefs, and lack of proper knowledge and counselling about contraception. ${ }^{3-5}$

In the UAE, with the tremendous development in various sectors, women are occupying diverse and important positions requiring them to be more productive socially and to have control over their reproduction. Despite the improvement in women's health, the UAE lacks family planning programs and education regarding contraception. ${ }^{6}$ The UAE also lack studies assessing contraceptive knowledge, attitudes, and use.

In 2001, a study was conducted in Al Ain city by GazalAswad and colleagues, which assessed the knowledge and practice of contraception in a sample of 400 women. ${ }^{6}$ Results showed that $41.5 \%$ of women were using contraceptives, and natural methods were the most commonly practiced methods. Further, the main reason for non-use was the perception that birth control is against religious beliefs. To the best of our knowledge, no other studies have addressed contraception in the UAE.

The aim of our study was to elucidate women's contraceptive knowledge, attitudes, and use in Abu Dhabi Island and to assess the distinct factors that affect each of them. This data will help identify attitudes toward and knowledge regarding family planning and help the government establish appropriate services and policies.

\section{METHODS}

This was a descriptive, cross-sectional questionnairebased study conducted at two randomly selected clinics practicing ambulatory healthcare services (AHS) in Abu Dhabi Island in the UAE. The study investigators completed an online training course "Protecting Human Research Participants" at the National Institute of Health. After meeting the criteria for research, as stated by the Health Authority of Abu Dhabi, the study proposal received approval from the AHS Human Ethics Research Committee on June 7, 2017.
Participants were women of reproductive age (18-54 years). They were married, divorced, widowed, or sexually active, and were visiting one of the two healthcare centers. Women who had had a hysterectomy or were menopausal for more than a year prior to the study and those who could not speak Arabic or English were excluded.

Using an online sample size calculator, the necessary calculated sample size was determined to be 384 , with a $5 \%$ margin of error and a $95 \%$ confidence interval. ${ }^{7}$ According to Abu Dhabi's latest statistical data, the female population aged 15-54 years in Abu Dhabi Island was $463,548 .{ }^{8}$ We used random cluster sampling to select clinics in Abu Dhabi Island. Two clinics (Al Bateen and Al Rawda) out of six were selected. The sample size from each clinic was calculated based on the proportional number of patients attending each clinic. Between June 2017 and March 2018, 384 eligible women were recruited by simple randomization to voluntarily participate. All questionnaires were successfully completed.

A structured questionnaire was prepared based on data presented in other similar studies. ${ }^{6}$ It comprised four sections: socio-demographics and contraceptive knowledge, attitudes, and use. The knowledge component contained 16 questions, and each correct item was given a score of one: scoring 0-5 was considered poor, 6-11 was considered fair, and 12-16 was considered good. Five items assessed women's attitudes: scoring 0-1 was considered negative, 2-3 was considered neutral, and 4-5 was considered positive. Contraception use was assessed with four items: use of contraception, method used, the reason behind using the preferred method, and reasons for non-use. Contraindications, methods of sterility, and protection against sexually transmitted infections (STIs) were assessed as well.

\section{Questionnaire}

The questionnaire was prepared in both English and Arabic. We also conducted a pilot study, which included 20 patients seen at Al Bateen healthcare center, and the questionnaire was modified accordingly. Participants were given clear instructions on the process of participation and assured that it was voluntary. An information sheet and a consent form were attached to the questionnaire, which highlighted the research significance, purpose, and confidentiality and all participants provided written consent. All questionnaires were completed, which took an average of 7 minutes.

\section{Statistical analysis}

Data were analyzed using SPSS version 18 . We used chisquare $(\chi 2)$-tests and Pearson's correlation coefficients (r). P-values $<.05$ were considered significant. 


\section{RESULTS}

\section{Participants' socio-demographic characteristics}

Participants' socio-demographic characteristics are shown in Table 1. Nearly half the samples were aged 3039 years, with an almost equal percentage of national and non-national participants. Almost all had at least a university education, and most were employed, had children, and had a sufficient family income for more than 10 years.

Table 1: Participants' socio-demographic characteristics $(\mathrm{N}=384)$.

\begin{tabular}{|c|c|c|}
\hline Characteristic & n & $(\%)$ \\
\hline \multicolumn{3}{|l|}{ Age $(n=382)$} \\
\hline 18-29 years & 105 & $(27.5)$ \\
\hline $30-39$ years & 171 & $(44.8)$ \\
\hline$\geq 40$ years & 106 & $(27.7)$ \\
\hline \multicolumn{3}{|l|}{ Nationality $(n=379)$} \\
\hline UAE national & 182 & $(48)$ \\
\hline Non-national & 197 & $(52)$ \\
\hline \multicolumn{3}{|c|}{ Education level $(n=378)$} \\
\hline High school or less & 6 & $(1.6)$ \\
\hline University or above & 372 & $(98.4)$ \\
\hline \multicolumn{3}{|l|}{ Occupation $(n=381)$} \\
\hline Unemployed & 155 & $(40.7)$ \\
\hline Employed & 226 & $(59.3)$ \\
\hline \multicolumn{3}{|c|}{ Number of children $(n=381)$} \\
\hline No children & 32 & $(8.4)$ \\
\hline Have children & 349 & $(91.6)$ \\
\hline \multicolumn{3}{|c|}{ Sex of children $(n=379)$} \\
\hline No children & 31 & $(8.2)$ \\
\hline Mostly boys & 135 & $(35.6)$ \\
\hline Mostly girls & 132 & $(34.8)$ \\
\hline Equal number & 81 & $(21.4)$ \\
\hline \multicolumn{3}{|c|}{ Years of marriage $(n=380)$} \\
\hline$<5$ years & 99 & $(26.1)$ \\
\hline $5-10$ years & 108 & $(28.4)$ \\
\hline$>10$ years & 173 & $(45.5)$ \\
\hline \multicolumn{3}{|c|}{ Family income $(n=376)$} \\
\hline Insufficient & 29 & $(7.7)$ \\
\hline Sufficient & 261 & $(69.4)$ \\
\hline Sufficient and saving & 86 & $(22.9)$ \\
\hline
\end{tabular}

\section{Contraceptive knowledge}

Women's knowledge scores were as follows: good = $23.7 \%$, fair $=52.1 \%$ and poor $=24.2 \%$. Table 2 displays the results of the knowledge questions. Most knew that combined oral contraceptive pills are contraindicated in patients with breast cancer; however, less than half knew this concerning patients with blood disorders, migraine history, or smokers aged > 35 years. Regarding knowledge about permanent infertility after the use of different contraceptive methods, more than half of the women knew that tubal ligation and vasectomy were permanent methods of contraception. Most correctly knew that injectables and intrauterine devices (IUDs) do not result in permanent infertility.

Moreover, while assessing the knowledge about protection against STIs, we found that most were aware that condoms protect against STIs. Further, most knew that injectables, oral contraceptive pills, and IUDs do not protect against STIs.

Table 2: Knowledge questions answered correctly $(\mathbf{N}=384)$.

\begin{tabular}{|lll|}
\hline Question & n & $(\%)$ \\
\hline $\begin{array}{l}\text { Patients with breast cancer cannot use } \\
\text { COCP }\end{array}$ & 198 & $(51.6)$ \\
\hline $\begin{array}{l}\text { Patients with kidney stones can use } \\
\text { COCP }\end{array}$ & 229 & $(59.6)$ \\
\hline Patients with migraines cannot use COCP & 78 & $(20.3)$ \\
\hline Patients with asthma can use COCP & 267 & $(69.5)$ \\
\hline $\begin{array}{l}\text { Patients with polycystic ovary syndrome } \\
\text { can use COCP }\end{array}$ & 171 & $(44.5)$ \\
\hline $\begin{array}{l}\text { Patient with blood disorders cannot use } \\
\text { COCP }\end{array}$ & 150 & $(39.1)$ \\
\hline $\begin{array}{l}\text { Patients with gastroesophageal reflux } \\
\text { disease can use COCP }\end{array}$ & 266 & $(69.3)$ \\
\hline $\begin{array}{l}\text { Smokers aged older than 35 years cannot } \\
\text { use COCP }\end{array}$ & 58 & $(15.1)$ \\
\hline $\begin{array}{l}\text { IUDs do not cause permanent infertility } \\
\text { Injectable contraception use cannot lead } \\
\text { to permanent infertility }\end{array}$ & 314 & $(81.8)$ \\
\hline $\begin{array}{l}\text { Vasectomies can lead to permanent } \\
\text { infertility }\end{array}$ & 219 & $(83.3)$ \\
\hline $\begin{array}{l}\text { Tubal ligation can lead to permanent } \\
\text { infertility }\end{array}$ & 240 & $(62.5)$ \\
\hline $\begin{array}{l}\text { Oral pills cannot protect against STIs } \\
\text { Injectable contraceptives cannot protect } \\
\text { against STIs }\end{array}$ & 328 & $(85.4)$ \\
\hline \begin{tabular}{l} 
Condoms can protect against STIs \\
\hline IUDs cannot protect against STIs
\end{tabular} & 329 & $(85.7)$ \\
\hline $\begin{array}{l}\text { combined oral contraceptive pills; bintrauterine devices; } \\
\text { 'sexually transmitted infections }\end{array}$ & $(79.7)$ \\
\hline
\end{tabular}

\section{Factors affecting contraceptive knowledge}

Various factors influenced women's contraceptive knowledge. Education level was significantly related to knowledge; specifically, women who had a lower education level displayed significantly poorer knowledge scores than did those with more education. There was also a significant relationship between women's employment status and knowledge: unemployed participants had significantly poorer knowledge compared to employed participants. Moreover, knowledge was significantly related to women's economic status: participants with a "sufficient and saving" family income had significantly better knowledge scores than did participants with an insufficient income. 
Lastly, those with a positive attitude toward contraception had significantly better knowledge compared to those with a negative attitude. There was no significant relationship between women's knowledge and age, nationality, number or sex of children, years of marriage, or contraception use (Table 3 ).

Table 3: Factors affecting women's knowledge of contraception $(\mathrm{N}=384)$.

\begin{tabular}{|c|c|c|c|c|}
\hline \multirow[t]{2}{*}{ Characteristic } & \multicolumn{3}{|c|}{ Knowledge level } & \multirow[t]{2}{*}{ P-value } \\
\hline & Good, n (\%) & Fair, n (\%) & Poor, n (\%) & \\
\hline \multicolumn{5}{|l|}{ Age } \\
\hline 18-29 years & $23(21.9)$ & $59(56.2)$ & $23(21.9)$ & \multirow{3}{*}{.559} \\
\hline $30-39$ years & $40(23.4)$ & $84(49.1)$ & $47(27.5)$ & \\
\hline$\geq 40$ years & $28(26.4)$ & $57(53.8)$ & $21(19.8)$ & \\
\hline \multicolumn{5}{|l|}{ Nationality } \\
\hline UAE national & $44(24.2)$ & $94(51.6)$ & $44(24.2)$ & \multirow{2}{*}{.973} \\
\hline Non-national & $47(23.9)$ & $104(52.8)$ & $46(23.4)$ & \\
\hline \multicolumn{5}{|l|}{ Education level } \\
\hline High school or less & $14(15.2)$ & $50(54.3)$ & $28(30.4)$ & \multirow{2}{*}{.042} \\
\hline University or above & $77(26.9)$ & $147(51.4)$ & $62(21.7)$ & \\
\hline \multicolumn{5}{|l|}{ Occupation } \\
\hline Unemployed & $25(16.1)$ & $88(56.8)$ & $42(27.1)$ & \multirow{2}{*}{.013} \\
\hline Employed & $66(29.2)$ & $110(48.7)$ & $50(22.1)$ & \\
\hline \multicolumn{5}{|l|}{ Number of children } \\
\hline No children & $6(18.8)$ & $22(68.8)$ & $4(12.5)$ & \multirow{2}{*}{.128} \\
\hline Have children & $85(24.4)$ & $177(50.7)$ & $87(24.9)$ & \\
\hline \multicolumn{5}{|l|}{ Sex of children } \\
\hline No children & $6(19.4)$ & $21(67.7)$ & $4(12.9)$ & \multirow{4}{*}{.177} \\
\hline Mostly boys & $40(29.6)$ & $62(45.9)$ & $33(24.4)$ & \\
\hline Mostly girls & $32(24.2)$ & $69(52.3)$ & $31(23.5)$ & \\
\hline Equal number & $13(16)$ & $46(56.8)$ & $22(27.2)$ & \\
\hline \multicolumn{5}{|l|}{ Years of marriage } \\
\hline$<5$ years & $22(22.2)$ & $53(53.5)$ & $24(24.2)$ & \multirow{3}{*}{.934} \\
\hline $5-10$ years & $29(26.9)$ & $53(49.1)$ & $26(24.1)$ & \\
\hline$>10$ years & $40(23.1)$ & $92(53.2)$ & $41(23.7)$ & \\
\hline \multicolumn{5}{|l|}{ Family income } \\
\hline Insufficient & $7(24.1)$ & $13(44.8)$ & $9(31)$ & \multirow{3}{*}{.005} \\
\hline Sufficient & $51(19.5)$ & $139(53.3)$ & $71(27.2)$ & \\
\hline Sufficient and saving & $31(36)$ & $45(52.3)$ & $10(11.6)$ & \\
\hline \multicolumn{5}{|l|}{ Attitude } \\
\hline Positive & $61(30.7)$ & $107(53.8)$ & $31(15.6)$ & \multirow{3}{*}{$<.001$} \\
\hline Neutral & $28(17.9)$ & $81(51.9)$ & $47(30.1)$ & \\
\hline Negative & $1(5.9)$ & $7(41.2)$ & $9(52.9)$ & \\
\hline \multicolumn{5}{|l|}{ Use of contraception } \\
\hline Used & $68(25.8)$ & $134(50.8)$ & $62(23.5)$ & \multirow{2}{*}{.337} \\
\hline Never used & $20(19.6)$ & $60(58.8)$ & $22(21.6)$ & \\
\hline
\end{tabular}

\section{Contraceptive attitude}

Most women held a positive attitude toward contraception use $(53.5 \%)$, while $41.9 \%$ and $4.6 \%$ of women exhibited neutral and negative attitudes, respectively. Most women believed that discussion between couples regarding contraception is vital (88.9\%), that birth-control education should be provided to all women prior to marriage (92\%), and that family planning is important for women's physical and mental well-being $(89.8 \%)$.

On the other hand, $46.1 \%$ of women believed that contraception has negative health outcomes and should not be used, and $23.7 \%$ believed that contraception use should be legally regulated to promote population growth. 
Table 4: Factors affecting women's attitudes toward contraception $(\mathrm{N}=384)$.

\begin{tabular}{|c|c|c|c|c|}
\hline \multirow[t]{2}{*}{ Factor } & \multicolumn{3}{|l|}{ Attitude } & \multirow[t]{2}{*}{ P-value } \\
\hline & Positive, n (\%) & Neutral, n (\%) & Negative, n (\%) & \\
\hline \multicolumn{5}{|l|}{ Age } \\
\hline $18-29$ years & $66(62.9)$ & $35(33.3)$ & $4(3.8)$ & \multirow{3}{*}{0.239} \\
\hline 30-39 years & $84(50.3)$ & $74(44.3)$ & $9(5.4)$ & \\
\hline$\geq 40$ years & $48(49)$ & $46(46.9)$ & $4(4.1)$ & \\
\hline \multicolumn{5}{|l|}{ Nationality } \\
\hline UAE national & $104(58.1)$ & 67 (37.4) & $8(4.5)$ & \multirow{2}{*}{0.340} \\
\hline Non-national & $95(50.5)$ & $84(44.7)$ & $9(4.8)$ & \\
\hline \multicolumn{5}{|l|}{ Education level } \\
\hline High school or less & $1(16.7)$ & $4(66.7)$ & $1(16.7)$ & \multirow{2}{*}{0.111} \\
\hline University or above & $196(54.4)$ & $148(41.1)$ & $16(4.4)$ & \\
\hline \multicolumn{5}{|l|}{ Occupation } \\
\hline Unemployed & $76(50)$ & $67(44.1)$ & $9(5.9)$ & \multirow{2}{*}{0.376} \\
\hline Employed & $122(56.2)$ & $87(40.1)$ & $8(3.7)$ & \\
\hline \multicolumn{5}{|l|}{ Number of children } \\
\hline No children & $14(43.8)$ & $15(46.9)$ & $3(9.4)$ & \multirow{2}{*}{0.274} \\
\hline Have children & $184(54.6)$ & $139(41.2)$ & $14(4.2)$ & \\
\hline \multicolumn{5}{|l|}{ Sex of children } \\
\hline No children & $13(41.9)$ & $15(48.4)$ & $3(9.7)$ & \multirow{4}{*}{0.444} \\
\hline Mostly boys & $75(59.5)$ & $45(35.7)$ & $6(4.8)$ & \\
\hline Mostly girls & $70(53.4)$ & $57(43.5)$ & $4(3.1)$ & \\
\hline Equal number & $40(50.6)$ & $35(44.3)$ & $4(5.1)$ & \\
\hline \multicolumn{5}{|l|}{ Years of marriage } \\
\hline$<5$ years & $54(55.7)$ & $39(40.2)$ & $4(4.1)$ & \multirow{3}{*}{0.996} \\
\hline $5-10$ years & $56(53.3)$ & 44 (41.9) & $5(4.8)$ & \\
\hline$>10$ years & 89 (53.6) & 69 (41.6) & $8(4.8)$ & \\
\hline \multicolumn{5}{|l|}{ Family income } \\
\hline Insufficient & $18(64.3)$ & $7(25)$ & $3(10.7)$ & \multirow{3}{*}{0.051} \\
\hline Sufficient & $133(52.8)$ & $105(41.7)$ & $14(5.6)$ & \\
\hline Sufficient and saving & $46(54.1)$ & $39(45.9)$ & $0(0)$ & \\
\hline \multicolumn{5}{|l|}{ Contraception use } \\
\hline Used & $151(57.6)$ & $105(40.1)$ & $6(2.3)$ & \multirow{2}{*}{0.001} \\
\hline Never used & $43(43)$ & $46(46)$ & $11(11)$ & \\
\hline
\end{tabular}

\section{Factors affecting contraceptive attitude}

As shown in Table 4, those who had never used any contraception had a significantly higher percentage of negative attitudes toward contraception as compared to those who had used contraception. There was no significant relationship between women's attitudes and age, nationality, number and sex of children, employment status, family income, or years of marriage.

\section{Contraception use}

As shown in Table 5, nearly three-quarters of participants had used contraceptives before, $48.3 \%$ were current users (i.e., used within the past year), and $23.8 \%$ were former users (i.e., not used within the last year). The most common methods used were natural methods and condoms, while the least used methods were tubal ligation and patch.
Concerning the reasons behind choosing a particular method, about half stated that it was based on the information they received from the media, which was followed by doctors' advice (about one-third). The reasons given by non-users are listed in Table 5. Fear of side effects was the most common reason. This was followed by the desire to have more children, fear of being permanently infertile, and women's husbands were against the use of contraception. The number of nonusers who believed that contraception went against religious teachings was negligible.

\section{Factors affecting contraception use}

Table 6 represents the factors affecting contraception use. Overall, three-quarters of the women who had children were using contraception, which was significantly higher as compared to those without children. Women who had an equal number of male and female children had a 
significantly higher percentage of contraception use as compared to those who had mostly boys or girls. Lastly, contraception use significantly increased with years of marriage.

Table 5: Contraception use, methods, and reasons among participating women $(\mathrm{N}=384)$.

\begin{tabular}{|c|c|c|}
\hline Use of contraception & n & $(\%)$ \\
\hline Used & 264 & $(72.1)$ \\
\hline Never used & 102 & $(27.9)$ \\
\hline Method & $\mathbf{n}$ & $(\%)$ \\
\hline Natural methods ${ }^{\mathrm{a}}$ & 168 & $(63.6)$ \\
\hline Condoms & 94 & $(35.6)$ \\
\hline Pills & 90 & $(34)$ \\
\hline Intrauterine devices & 89 & $(33.7)$ \\
\hline Injections & 18 & $(6.8)$ \\
\hline Tubal ligation & 7 & $(2.6)$ \\
\hline Implant & 3 & $(1.1)$ \\
\hline Patch & 0 & $(0)$ \\
\hline Reason for preferred method & $\mathbf{n}$ & $(\%)$ \\
\hline Media & 135 & $(54.2)$ \\
\hline Doctors' advice & 89 & $(35.7)$ \\
\hline Family members' advice & 39 & $(15.7)$ \\
\hline Side effects from other methods & 33 & $(13.3)$ \\
\hline $\begin{array}{l}\text { Disease limiting the use of other } \\
\text { methods }\end{array}$ & 13 & $(5.2)$ \\
\hline Failure of other methods & 11 & $(4.4)$ \\
\hline Reason for non-users & $\mathbf{n}$ & $(\%)$ \\
\hline Fear of side effects & 112 & $(51.9)$ \\
\hline Desire to have more children & 70 & $(32.6)$ \\
\hline Fear of sterility & 45 & $(20.9)$ \\
\hline Husbands' refusal & 43 & $(19.9)$ \\
\hline Ineffective in preventing pregnancy & 12 & $(5.6)$ \\
\hline Against religious teachings & 11 & $(5.1)$ \\
\hline Other reasons & 57 & $(26.4)$ \\
\hline
\end{tabular}

\section{DISCUSSION}

Socio-demographic determinants are indirectly associated with contraception through their effects on the behavior of women and their health status. The effect of these factors is well documented in other similar studies. ${ }^{5,9}$

The current study revealed that only around one-quarter of women had good knowledge about contraception. Most prior studies considered knowing the different contraceptive methods as "knowledge," without assessing women's real understating of contraception, for example, indications/contraindication, side effects, and other uses. This explains why other studies, such as those by GhazalAswad and colleagues, Sajid and colleagues, and Mubashar and colleagues, reported high knowledge rates reaching up to $99 \% .5,6,10$
It was interesting to find that more than half the women held a positive attitude toward contraception, and a negligible number held a negative attitude. The numbers in our findings are somewhat lower than what was found in similar studies conducted in Saudi Arabia and Ethiopia regarding positive attitude $(79.6 \%$ and $91 \%$, respectively). ${ }^{4,5}$ However, a study conducted in Riyadh, Saudi Arabia revealed that only $21.4 \%$ of women were in favor of using contraceptives, which was significantly influenced by their employment status and husbands' attitudes. ${ }^{11}$ As discussed earlier, women with a higher education level were more likely to have a positive attitude and higher rates of contraception use than those with less education. This is not surprising since those with higher education typically have more contraceptive knowledge and, since most are employed, they are usually in favor of family planning. Further, Tilahun and colleagues revealed that literacy was a significant factor promoting a positive attitude toward contraception. ${ }^{4}$

Despite the lower percentage of favorable attitudes toward contraception compared to other studies, nearly half the women in this study were current users, which is comparable to Arbab and colleagues' study in Qatar $(47.8 \%) .{ }^{12}$ However, our findings were slightly higher than those found by Ghazal-Aswad and colleagues in $\mathrm{Al}$ Ain $(41.5 \%)$ and Tilahun and colleagues in Ethiopia (43\%). ${ }^{4,6}$ Mubashar and colleagues showed a much higher percentage of contraception use (75.4\%); however, this could be higher because whether the researchers included both current and previous users was not specified. $^{5}$

Natural methods are preferred and are considered acceptable in most societies since they do not have side effects, are cost effective, and are easy to practice. ${ }^{4,6}$ Not surprisingly, natural methods were the most commonly used methods in the current study, followed by condoms, oral contraceptive pills, and IUDs. Sterilization was only used by a negligible number of women. Our results are somewhat similar to other studies. ${ }^{6}$ However, in Pakistan (Lahore), the most frequently used method was bilateral tubal ligation (20.83\%), followed by IUDs (13.08\%). ${ }^{9}$ It has been observed that the media plays a key role in women's preferred contraceptive method, followed by advice from doctors. ${ }^{3,5,13} \mathrm{We}$ believe that introducing and promoting modern contraceptives via these means will dramatically change the observed pattern of contraception use.

We revealed that fear of side effects, the desire to have more children, and fear of permanent infertility was the main reasons behind contraception avoidance. Interestingly, non-use because of religious factors was very low as compared to what Ghazal-Aswad found in $2001(70.9 \%) .{ }^{6}$ Perhaps there has been a societal change in attitudes concerning religious teachings and contraception use. 
Further, women with children and those who were married longer were more commonly using contraceptives than those without children and those married for a shorter duration, which can be explained by their better understanding and experience with contraception and a greater desire for family planning and spacing between children. Owing to cultural concepts, dissatisfaction, family pressure, and the desire to have both sexes of children, we found that women with more female or male children were less likely to have used contraception, perhaps in the hope of having the desired sex with each pregnancy.

Table 6: Factors affecting women's use of contraception $(N=384)$.

\begin{tabular}{|c|c|c|c|}
\hline \multirow[t]{2}{*}{ Factor } & \multicolumn{2}{|l|}{ Use of contraception } & \multirow[t]{2}{*}{ P-value } \\
\hline & Using contraception, $\mathbf{n}(\%)$ & Never used contraception, n (\%) & \\
\hline \multicolumn{4}{|l|}{ Age } \\
\hline $18-29$ years & $70(68)$ & $33(32)$ & \multirow{3}{*}{0.334} \\
\hline $30-39$ years & $126(75.9)$ & $40(24.1)$ & \\
\hline$\geq 40$ years & $67(70.5)$ & $28(29.5)$ & \\
\hline \multicolumn{4}{|l|}{ Nationality } \\
\hline UAE national & $126(71.2)$ & $51(28.8)$ & \multirow{2}{*}{0.643} \\
\hline Non-national & $135(73.4)$ & 49 (26.6) & \\
\hline \multicolumn{4}{|l|}{ Education level } \\
\hline High school or less & $5(83.3)$ & $1(16.7)$ & \multirow{2}{*}{0.534} \\
\hline University or above & $255(71.8)$ & $100(28.2)$ & \\
\hline \multicolumn{4}{|l|}{ Occupation } \\
\hline Unemployed & $108(72)$ & $42(28)$ & \multirow{2}{*}{0.950} \\
\hline Employed & $154(72.3)$ & $59(27.7)$ & \\
\hline \multicolumn{4}{|l|}{ Number of children } \\
\hline No children & $13(40.6)$ & $19(59.4)$ & \multirow{2}{*}{$<0.001$} \\
\hline Have children & $250(75.5)$ & $81(24.5)$ & \\
\hline \multicolumn{4}{|l|}{ Sex of children } \\
\hline No children & $89(69.5)$ & $39(30.5)$ & \multirow{4}{*}{$<0.001$} \\
\hline Mostly boys & $97(77)$ & $29(23)$ & \\
\hline Mostly girls & $62(81.6)$ & $14(18.4)$ & \\
\hline \multirow{2}{*}{\multicolumn{4}{|c|}{$\begin{array}{l}\text { Equal number } \\
\text { Years of marriage }\end{array}$}} \\
\hline & & & \\
\hline$<5$ years & $63(64.9)$ & $34(35.1)$ & \multirow{3}{*}{0.008} \\
\hline $5-10$ years & $68(66.7)$ & $34(33.3)$ & \\
\hline$>10$ years & $131(80.4)$ & $32(19.6)$ & \\
\hline \multicolumn{4}{|l|}{ Family income } \\
\hline Insufficient & $25(86.2)$ & $4(13.8)$ & \multirow{3}{*}{.213} \\
\hline Sufficient & $177(70.8)$ & $73(29.2)$ & \\
\hline Sufficient and saving & $58(71.6)$ & $23(28.4)$ & \\
\hline
\end{tabular}

\section{CONCLUSION}

We conclude that, even though less than one third of the current sample of women had good knowledge about contraception, more than half of them held a positive attitude and more than two thirds had already used contraception. Despite the advancement and availability of modern contraceptive methods, natural methods were still the most commonly used. The reasons given by nonusers were fear of side effects, the desire to have more children, and fear of permanent infertility. Family planning is vital, and efforts should be made to overcome any factors that negate the use of contraception. Proper education will eliminate women's misconceptions and uncertainties toward contraception and will likely increase the use of modern contraceptives.

\section{ACKNOWLEDGMENTS}

Authors would like to thank all the women for their participation and the healthcare providers in Abu Dhabi Island for their contribution.

Funding: No funding sources

Conflict of interest: None declared

Ethical approval: The study was approved by the Institutional Ethics Committee 


\section{REFERENCES}

1. World Health Organization. Family planning. Available at; http://www.who.int/topics/family_ planning/en/). Accessed October 2018.

2. Sedgh G, Singh S, Hussain R. Intended and unintended pregnancies worldwide in 2012 and recent trends. Stud Fam Plann. 2014;45(3):301-14.

3. Pegu B, Gaur B, Sharma N, Singh A. Knowledge, attitude and practices of contraception among married women. Int J Reprod Contracept Obstet Gynecol. 2014;385-8.

4. Tilahun T, Coene G, Luchters S, Kassahun W, Leye E, Temmerman M. Family planning knowledge, attitude and practice among married couples in Jimma Zone, Ethiopia. PLoS One. 2013;8(4):e61335.

5. Mubashar H, Almushait M, Sukit B, Shaamash A, Handady S, Almutawa N. Knowledge, attitude, and practice of contraception among Saudi women in Aseer Region, Saudi Arabi. Bangladesh J Med Sci. 2016;15(3):430-4.

6. Ghazal-Aswad S, Rizk D, Al-Khoori S, Shaheen H. Knowledge and practice of contraception among United Arab Emirates women. Int J Gynecol Obstet. 2000;70.

7. Sample size calculator. Available at; http://www.surveysystem.com/sscalc.htm. Accessed June 2017.

8. Statistical year book of Abu Dhabi. 2017. Available at: https://www.scad.ae/Release\%20Documents/SYB _2017_EN.PDF. Accessed June 2017.
9. Zuberi K, Salman H, Virji N, Sana S, Kumari S, Zehra N. A hospital-based comparative study of the knowledge, attitudes and practices of family planning among women belonging to different socioeconomic status. J Pak Med Assoc. 2015;65(5):57984.

10. Sajid A, Malik S. Knowledge, attitude and practice of contraception among multiparous women at Lady Aitchison Hospital, Lahore. Annals of King Edward Medical University. 2010;16(4):266.

11. Mahboub S, Abdelkader S, Al-Muhanna A, AlMusallam F, Al-Ghannam J, Al-Munyif S. Attitude towards contraceptives use among Saudi women. Int J Healthc Sci. 2015;2:331-9.

12. Arbab A, Bener A, Abdulmalik M. Prevalence, awareness and determinants of contraceptive use in Qatari women. East Mediterr Health J. 2011;17(1).

13. Prachi R, Das G, Ankur B, Shipra J, Binita K. A study of knowledge, attitude and practice of family planning among the women of reproductive age group in Sikkim. J Obstet Gynecol India. 2008;58(1):63-7.

Cite this article as: Taheri S, Sereidi AA, Mamari SA, Darwish E. Contraceptive knowledge, attitudes, and use among women visiting primary healthcare centers in Abu Dhabi Island. Int J Reprod Contracept Obstet Gynecol 2019;8:1827-34. 